\title{
Pharmaceutical Developability of Clinically Relevant Flavonoids like Curcumin: Why are We Failing?
}

\author{
Pratap Singh D*, Jayanthi C and Joshi Hanumanthachar K
}

Department of Pharmaceutics, Sarada Vilas College of Pharmacy, Mysore, 570004, Karnataka, India

*Corresponding author: Pratap Singh D, Department of Pharmaceutics, Sarada Vilas College of Pharmacy, Mysore, 570004, Karnataka, India, Tel: +919714756511; E-mail: devendra.mysore@gmail.com

Received date: January 30, 2017; Accepted date: February 13, 2017; Published date: February 20, 2017

Copyright: (C) 2017 Pratap Singh D, et al. This is an open-access article distributed under the terms of the Creative Commons Attribution License, which permits unrestricted use, distribution, and reproduction in any medium, provided the original author and source are credited.

Citation: Pratap Singh D, Jayanthi C, Joshi Hanumanthachar K, Pharmaceutical Developability of Clinically Relevant Flavonoids like Curcumin: Why are We Failing? Med Clin Rev. 2017, 3:1.

\section{Abstract}

Flavonoids are promising therapeutic class of polyphenolic biomolecules with the potential to alleviate many severe disease states with multi-factorial pathogenesis because of their inherent ability to regulate key biological cascades at the molecular, cellular and organism levels. However, these important polyphenolic compounds frequently pose drug delivery challenges to scientists and produce inefficient pharmacokineticpharmacodynamic activities. Importantly, despite their therapeutic potential and the focus of the scientists being on the formulation development front in the recent years, developing an ideal drug delivery system for some of the most important polyphenolic biomolecules such as curcumin is still a challenge. Hence, the basic intent of writing this article is to bring back the focus of the formulation scientists on one of the key physicochemical properties of these important biomolecules i.e., the importance of $\mathrm{pH}$-stability profile of flavonoids, which could play vital role in the formulation developability aspects of important biomolecules such as curcumin by the selection of an ideal dosage form.

Keywords: Pharmaceutical developability; Curcumin; Solubility; Stability; Flavonoids

\section{Introduction}

Flavonoids are promising therapeutic class of polyphenolic biomolecules with the potential to alleviate many severe disease states because of their inherent ability to regulate key biological cascades [1-7]. These important polyphenolic biomolecules have received considerable attention in the recent past as summarized [8-10]. Curcumin which is chemically 1,7-bis (4-hydroxy-3-methoxyphenol)-1,6 heptadiene-3,5-dione or diferuloylmethane, is one such polyphenol belonging to a class of compounds known as curcuminoids, isolated from the Indian spice Curcuma Longa
Linn which has been used as an Ayurvedic medicine from thousands of years $[11,12]$. Just like another well studied biomolecule, quercetin $[5-7,13,14]$, curcumin has also received considerable attention over the past decades, which is mainly due to its diverse biological activities, including but not limited to antioxidant, anti-inflammatory, anti-arthritic, anti-ulcer, anti-diabetic, anti-bacterial activities and its potential therapeutic applications in a large number of diseases including but not limited to cancer and neurodegenerative diseases (Figure 1) [4,11,12,15-19]. Hence, curcumin is used as a supplement/neutraceutical in several countries, including but not limited to India, Japan, America, Thailand, China, Korea, Turkey, South Africa, Nepal, Bangladesh, Sri Lanka and Pakistan owing to its perceived potential health benefits [20].

\section{Curcumin Research: What is the Current Scenario?}

In human clinical trials, curcumin has been found to be safe and efficacious, and the U.S. Food and Drug Administration has thus approved curcumin as a "Generally Regarded as Safe (GRAS)" compound [21,22]. Nonetheless, although inexpensive, apparently well tolerated, and potentially active, curcumin has yet not been approved for treatment of any human disease/ailment [20]. Despite thousands of research papers, wide range of pharmacological activities of curcumin reported in the past decades, more than 120 reported clinical trials, still a paradox and uncertainty remains regarding the pharmacology of curcumin owing to its physicochemical properties leading to the poor systemic bioavailability $[23,24]$. Such is the present scenario, that, on one hand some groups in the scientific community believes that curcumin is an ideal drug candidate owing to its reported and perceived therapeutic benefits, and on the other hand some other groups have clearly said that working on curcumin is simply "waste of time" $[10,23,24]$. However, in between these two schools of thoughts, there is an area of research which needs to be focused and indeed, now, the time is apt to apply the inter-disciplinary approach for the pharmaceutical developability of curcumin. 
Curcumin has been reported to mitigate the mitochondrial dysfunction and Adenosine Tri Phosphate (ATP) loss [25], generation of Reactive Oxygen Species (ROS) [26], rise in the levels of nuclear factor kappa B (NF-KB) and pro-inflammatory cytokines like tumor necrosis factor [27-29] and prevents Tight Junction (TJ) dysfunction and thereby Intestinal Permeability (IP) alteration [30]

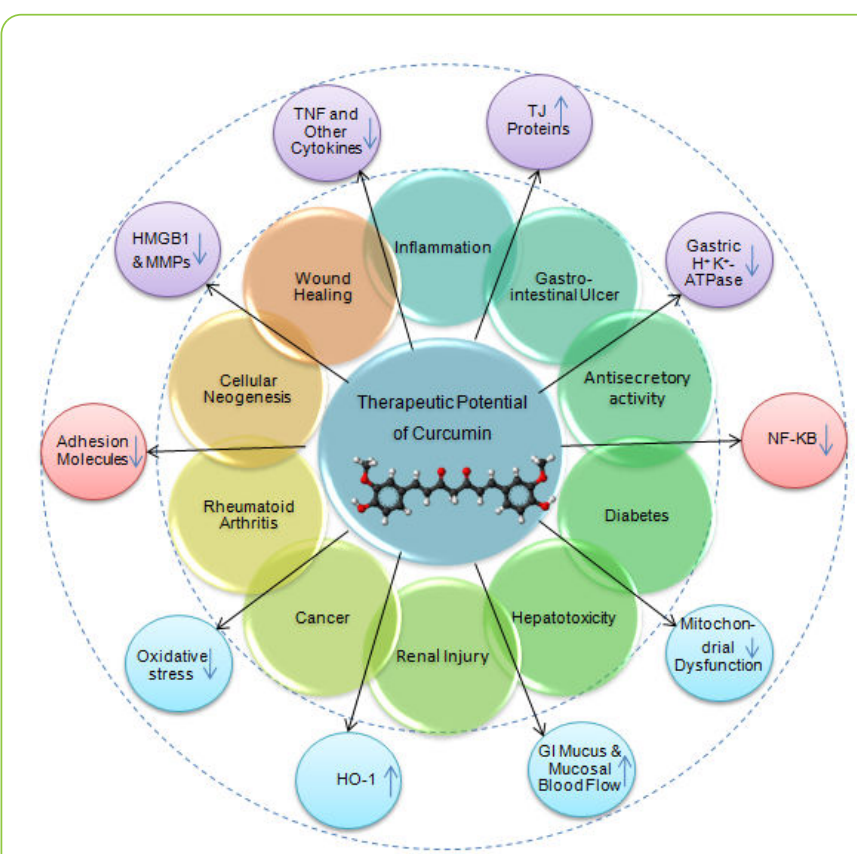

Figure 1: Therapeutic potential of Curcumin.

It has been demonstrated to downregulate high mobility group box 1 (HMGB-1) [31] and Matrix Metalloproteinases (MMPs) levels [26], enhance haeme oxygenase-1 (HO-1) levels [32], decrease adhesion molecules [28] and has been shown to inhibit gastric $\mathrm{H}^{+} \mathrm{K}^{+}$-ATPase activity [33], which have been identified as some of the important players in the etiopathogenesis of variety of diseases against whom the potential of curcumin has been reported in the scientific literature.

\section{Designing an Ideal Drug Delivery System for Curcumin: What's New?}

Curcumin faces many challenges in relation to its successful pharmaceutical developability, which are mainly related to its low solubility and stability in physiologically relevant solutions. Indeed, many researchers have highlighted previously that, curcumin is hydrophobic in nature and is highly unstable undergoing rapid hydrolytic degradation in neutral or alkaline conditions, but is stable below pH 6.0 [34-36]. In addition, there is yet another challenge; curcumin is insoluble in water under acidic or neutral conditions but dissolves in alkaline environment; the solutions in which it is unstable. Many dosage forms incorporating curcumin including the nanotechnology-based novel strategies have been reported in the literature [4,15,37-42]. However, while designing the dosage forms for curcumin, the data related to the stability profile of the curcumin has been overlooked. Here, in the present paper, authors emphasize on the opportunities for the thoughtful application of the $\mathrm{pH}$-stability profile data in the development of the ideal dosage forms for flavonoids so that this promising class of natural molecules could be brought in the forefront of our armamentarium against variety of diseases.

\section{Developing curcumin loaded gastroretentive drug delivery system (GRDDS): The way forward}

In light of the physicochemical properties of curcumin, delivering curcumin as a Gastroretentive Drug Delivery System (GRDDS) would be an ideal approach to perk up the effectiveness of curcumin by prolonging its gastric residence so that the drug is released in the vicinity of its absorption window for an extended period of time and remains stable too [43-47]. Among the numerous approaches used to improve the gastric residence time of Drug Delivery System (DDS), the vital ones include, single and multiple-unit floating systems, bioadhesive systems, swelling unfoldable and expanding systems, raft forming systems and high-density systems [43-46]. However, while selecting the ideal approach of gastric retention for curcumin, the solubility cum stability profile of curcumin should be kept in mind so as to have a stable delivery system with ideal dissolution characteristics.

\section{Discussion and Conclusion}

Advancements in modern science have provided a scientific basis for the practice of using turmeric and/or curcumin therapy against numerous human diseases/ailments in innumerable cultures and societies in many countries. This important polyphenolic biomolecule (curcumin) has been shown to target multiple signaling molecules and has shown activities at the molecular, cellular and organism levels that provide a basis for its use against variety of human diseases with multi-factorial pathogenesis. The scientific fraternity is today looking for ways to address the issues related to the pharmaceutical developability of curcumin. In this purview, one of the major concerns associated with the pharmaceutical developability of curcumin is its low oral bioavailability that can be attributed to its low solubility, poor absorption, high instability in alkaline media and rapid elimination from the body. Numerous approaches including the nanotechnology based delivery systems have been reported in the literature so as to enhance the bioavailability of curcumin. However, looking at the physico-chemical properties of curcumin and its therapeutic potential, developing curcumin based GRDDS could be highly beneficial. Therefore, further research is required to determine the optimal dosage, bioavailability, and bio-efficacy of curcumin-based GRDDS in the near future. We believe that this approach could be highly beneficial in answering at least some questions related to the paradox and uncertainty around curcumin. Translation of this knowledge is eagerly awaited. 


\section{Acknowledgement}

Authors are thankful to management of Sarada Vilas College of Pharmacy, Mysore, Karnataka, for providing all the facilities for the successful completion of the work.

\section{References}

1. Ravishankar D, Rajora A, Francesca G, Osborn HMI (2013) Flavonoids as prospective compounds for anti-cancer therapy. Int J Biochem Cell Biol 45: 2821-2831.

2. Angelini A, Di Ilio C, Castellani ML, Conti P, Cuccurullo F (2009) Modulation of multidrug resistance p-glycoprotein activity by flavonoids and honokiol in human doxorubicin-resistant sarcoma cells (MES-SA/DX-5): implications for natural sedatives as chemosensitizing agents in cancer therapy. J Biolo Reg Homeostat Agents 24: 197-205.

3. Naruszewicz M, Łaniewska I, Barbara M, Dłużniewski M (2007) Combination therapy of statin with flavonoids rich extract from chokeberry fruits enhanced reduction in cardiovascular risk markers in patients after myocardial infraction (MI). Atherosclerosis 194: e179-e184.

4. Singh D, Joshi H (2013) Role of curcumin in the management of Cognitive disorders. in National Conference on "Current Trends in the Treatment and Management of Learning Disabilities and Cognitive Disorders" held at Sarada Vilas College of Pharmacy, Mysore.

5. Singh D, Niivsarkar M (2016) Unravelling a novel therapeutic strategy for the management of NSAID-induced gastroenteropathy: Addressing an unannounced emergency. In: 49th Annual Conference of Indian Pharmacological Society; IPSCON-2016, At PGIMER, Chandigarh.

6. Singh D, Niivsarkar M (2016) Co-administration of quercetin with pantoprazole sodium prevents NSAID-induced severe gastroenteropathic damage efficiently: Evidence from a preclinical study in rats. Exp Toxic Pathol.

7. Singh D, Niivsarkar M (2016) Quercetin and Quercetin based compositions for preventing or treating Nonsteroidal antiinflammatory drugs-induced gastroenteropathy. In Patent App. 201621021085

8. Scicchitano P, Matteo C, Maria M, Pietro AM, Maria LM, et al. (2014) Nutraceuticals and dyslipidaemia: Beyond the common therapeutics. J Funct Food 6: 11-32.

9. Aggarwal BB, Harikumar KB (2009) Potential therapeutic effects of curcumin, the anti-inflammatory agent, against neurodegenerative, cardiovascular, pulmonary, metabolic, autoimmune and neoplastic diseases. Int J Biochem Cell Biol 41: 40-59.

10. Goel A, Kunnumakkara AB, Aggarwal BB (2008) Curcumin as "Curecumin": from kitchen to clinic. Biochem Pharmacol 75: 787-809.

11. Anand P, Kunnumakkara AB, Newman RA, Aggarwal BB (2007) Bioavailability of curcumin: problems and promises. Mol Pharm 4: 807-818.

12. Epstein J, Sanderson IR, MacDonald TT (2010) Curcumin as a therapeutic agent: the evidence from in vitro, animal and human studies. Br J Nutr 103: 1545-1557.

13. Singh D, Niivsarkar M (2016) A Novel Model for NSAID Induced Gastroenteropathy and the Proposed Role of TNF- $\alpha$ : Way
Forward for the Discovery of Futuristic Therapeutic Interventions, in 3rd Nirma Institute of Pharmacy International Conference-NIPiCON 2016 "Global Challenges in Drug Discovery, Development and Regulatory affairs" Ahmedabad.

14. Singh DP, Borse SP, Nivsarkar M (2016) A novel model for NSAID induced gastroenteropathy in rats. J Pharmacol Toxicol Methods 78: 66-75.

15. Singh DP, Jayanthi C, Joshi K, Hanumanthachar G (2013) Enhancement of aqueous solubility of curcumin by solid dispersion technology. World J Pharm Pharmaceut Sci 2: 4109-4120.

16. Liu W, Yingjie Z, Xueyuan H, Feng YC, Wenjun C, et al. (2016) Oral bioavailability of curcumin: problems and advancements. J Drug Target 24: 694-702.

17. Perrone D, Fatima A, Giovanni G, Mario D, Giuseppe T (2015) Biological and therapeutic activities, and anticancer properties of curcumin (Review). Exp Ther Med 10: 1615-1623.

18. Wilken R, Mysore VS, Marilene BW, Srivatsan ES (2011) Curcumin: A review of anti-cancer properties and therapeutic activity in head and neck squamous cell carcinoma. Mol Cancer 10: 12 .

19. Singh D, Niivsarkar $M$ (2016) Clinical importance of NSAID enteropathy: The relevance of Tumour Necrosis Factor as a promising target. Transl Res 175: 76-91.

20. Pulido-Moran M (2016) Curcumin and health. Molecules 21: 264.

21. Prasad S, Subash C Gupta, Tyagi AK, Aggarwal BB (2014) Curcumin, a component of golden spice: from bedside to bench and back. Biotechnol Adv 32: 1053-1064.

22. Gupta SC, Patchva S, Wonil K, Aggarwal BB (2012) Discovery of curcumin, a component of golden spice, and its miraculous biological activities. Clin Exp Pharmacol Physiol 39: 283-299.

23. Baker MM (2017) Deceptive curcumin offers cautionary tale for chemists. Nature 541: 144-145.

24. Shen L, Cui-Cui L, Chun-Yan A, Hong-Fang J (2016) How does curcumin work with poor bioavailability? Clues from experimental and theoretical studies. Scientific Reports 6 .

25. Sivalingam N, Basivireddy J, Balasubramanian KA, Jacob $M$ (2008) Curcumin attenuates indomethacin-induced oxidative stress and mitochondrial dysfunction. Arch Toxicol 82: 471-481.

26. Swarnakar S, Ganguly K, Kundu P, Banerjee A, Maity P, et al. (2005) Curcumin regulates expression and activity of matrix metalloproteinases 9 and 2 during prevention and healing of indomethacin-induced gastric ulcer. J Biol Chem 280: 9409-9415.

27. Singh S, Aggarwal BB (1995) Activation of transcription factor NF-KB is suppressed by curcumin (diferuloylmethane). J Biol Chem 270: 24995-25000.

28. Thong-Ngam D (2012) Curcumin prevents indomethacininduced gastropathy in rats. World J Gastroenterol 18: 1479-1484.

29. Singh DP, Borse SP, Nivsarkar M (2016) Clinical importance of nonsteroidal anti-inflammatory drug enteropathy: the relevance of tumor necrosis factor as a promising target. Translational Research.

30. Wang N, Wang Gai, JingXia H, JunJi M, Yan W, et al. (2012) Curcumin ameliorates hydrogen peroxide-induced epithelial barrier disruption by upregulating heme oxygenase-1 expression in human intestinal epithelial cells. Dig Dis Sci 57: 1792-1801. 
31. Gu Q, Honggeng G, Qin S, Yanyun Z, Huilin Y (2015) Curcumin attenuated acute Propionibacterium acnes-induced liver injury through inhibition of HMGB1 expression in mice. Int Immunopharmacol 24: 159-165.

32. Motterlini R, Roberta F, Rekha B, Colin G (2000) Curcumin, an antioxidant and anti-inflammatory agent, induces heme oxygenase- 1 and protects endothelial cells against oxidative stress. Free Radic Res Commun 28: 1303-1312.

33. Mei X, Donghui X, Sika X, Yanping Z, Shibo X (2012) Novel role of Zn (II)-curcumin in enhancing cell proliferation and adjusting proinflammatory cytokine-mediated oxidative damage of ethanol-induced acute gastric ulcers. Chem Biol Interact 197: 31-39.

34. Price LC, Buescher R (1997) Kinetics of alkaline degradation of the food pigments curcumin and curcuminoids. J Food Sci 62 : 267-269.

35. Wang YJ, Min-Hsiung P, Ann-Lii C, Liang-In L, Yuan-Soon H (1997) Stability of curcumin in buffer solutions and characterization of its degradation products. J Pharmaceut Biomed Anal 15: 1867-1876.

36. Lin JK, Pan MH, Lin-Shiau SY (2000) Recent studies on the biofunctions and biotransformations of curcumin. Biofactors 13 : 153-158.

37. Naksuriya O, Siriporn O, Raymond SM, Wim H (2014) Curcumin nanoformulations: a review of pharmaceutical properties and preclinical studies and clinical data related to cancer treatment. Biomaterials 35: 3365-3383.

38. Yallapu MM, Jaggi M, Chauhan SC (2012) Curcumin nanoformulations: a future nanomedicine for cancer. Drug Discov Today 17: 71-80.
39. Dhule SS, Patrice P, Frazier T, Walker R, Feldman J (2012) Curcumin-loaded $\gamma$-cyclodextrin liposomal nanoparticles as delivery vehicles for osteosarcoma. Nanomed Nanotech Biol Med 8: 440-451.

40. Wang P, Libin Z, Hao P, Yongwu L, Jian X (2013) The formulation and delivery of curcumin with solid lipid nanoparticles for the treatment of on non-small cell lung cancer both in vitro and in vivo. Materials Sci Eng: C 33: 4802-4808.

41. Reddy SM, Jayanthi DPSC, Joshi H (2008) Enhancement of Aqueous Solubility of Curcumin by Nanoformulation Technique. In Herbal Drug Research: Opportunities and Challenges.

42. Singh DP, Joshi H, Roopa G (2012) Enhancement of oral bioavailability of Curcumin by solid dispersion technology. in 64th Indian Pharmaceutical Congress (IPC).

43. Ganesh NS, Hanumanthachar Joshi GB, Jayanthi C, Singh DP (2013) Buoyant multiparticulate drug delivery-A focus on hydrogel beads. Int J Pharm Pharm Sci 2: 450-464.

44. Streubel A, Siepmann J, Bodmeier R (2006) Gastroretentive drug delivery systems. Expert Opin Drug Deliv 3: 217-233.

45. Streubel A, Siepmann J, Bodmeier R (2006) Drug delivery to the upper small intestine window using gastroretentive technologies. Curr Opin Pharmacol 6: 501-508.

46. Prajapati VD (2013) Raft forming system-An upcoming approach of gastroretentive drug delivery system. J Control Release 168: 151-165.

47. Chavanpatil MD, Jain P, Chaudhari S, Shear R, Vavia P (2006) Novel sustained release, swellable and bioadhesive gastroretentive drug delivery system for ofloxacin. Int J Pharm 316: 86-92. 